\title{
Association of monoctye expression of Toll-like receptor 4 and its related cytokines with coronary luminal stenosis
}

\author{
Bahador Bagheri ${ }^{1}$, Bahram Sohrabi ${ }^{2}$, Aliakbar Movassaghpur ${ }^{3}$, Simin Mashayekhi ${ }^{4}$, Afagh Garjani $^{5}$, \\ Mehriar Shokri $^{2}$, Mohammad Noori ${ }^{2}$, Alireza Garjani ${ }^{{ }^{*}}$ \\ ${ }^{1}$ Department of Pharmacology, Faculty of Pharmacy, Tabriz University of Medical Sciences, Tabriz, Iran \\ ${ }^{2}$ Shahid Madani Heart Hospital, Tabriz University of Medical Sciences, Tabriz, Iran \\ ${ }^{3}$ Hematology Research Centre, Tabriz University of Medical Sciences, Tabriz, Iran \\ ${ }^{4}$ Departmentof Clinical Pharmacy, Faculty of Pharmacy, Tabriz University of Medical Sciences, Tabriz, Iran \\ ${ }^{5}$ School of Medicine, Tabriz University of Medical Sciences, Tabriz, Iran \\ Email: "garjania@tbzmed.ac.ir, garjania2002@yahoo.com
}

Received 18 April 2013; revised 20 May 2013; accepted 30 May 2013

Copyright (C 2013 Bahador Bagheri et al. This is an open access article distributed under the Creative Commons Attribution License, which permits unrestricted use, distribution, and reproduction in any medium, provided the original work is properly cited.

\begin{abstract}
Toll-like receptors are well-defined barriers in innate immunity. Among them hTLR4 on the surface of monocytes, plays a critical role in the formation of atherosclerotic plaques, plaque instability and arterial remodeling through production of inflammatory cytokines. This study was designed to examine the association of hTLR4 monocyte expression and response with the severity of coronary stenosis in patients with stable angina (SA). Blood samples were obtained from 39 patients with SA who were scheduled for a coronary angiography and from 28 healthy volunteers. The samples were collected before the procedure. Expression of hTLR4 on $\mathrm{CD}^{+} 4^{+}$monocytes and serum levels of TNF- $\alpha$ and IL-1 $\beta$ were measured using flowcytometry and ELISA techniques respectively. Percentage stenosis diameter was measured by comparing the area of coronary stenosis to an adjacent normal segment of the vessel. Compared with control group, patients showed upregulation of hTLR4 $^{+} / \mathrm{CD}^{+} 4^{+}$monocytes. Furthermore, patients with more severe coronary stenosis exhibited enhanced expression of hTLR4 $^{+} / \mathrm{CD}_{14}{ }^{+}$monocytes $(p<0.01)$. This was paralleled by elevation in the serum levels of TNF- $\alpha(p<0.05)$ and IL-1 $\beta$. In addition, significant correlations were seen between percentage stenosis diameter and monocyte expression of hTLR4 as well as TNF- $\alpha$. hTLR4 monocytic expression and related cytokines are positively associated percentage stenosis diameter. These results suggest that hTLR4 activity may be involved in progression of atherosclerosis.
\end{abstract}

\footnotetext{
"Corresponding author.
}

Keywords: Atherosclerosis; Cytokines; Inflammation; hTLR4

\section{INTRODUCTION}

Atherosclerosis is the main cause of cardiovascular mortality. A significant body of evidence suggests that inflammation plays a key role in the formation of atherosclerotic plaques [1-3]. Toll like receptors (TLRs) are cell membrane receptors that are activated by different pathogen-associated molecular patterns (PAMPs) [4]. TLRs are widely considered as central element of innate immune system. Ten functional human TLRs (hTLR) have been identified so far [5]. Among them, hTLR4 is well recognized in cardiovascular disease particularly in the formation of atherosclerotic plaques [6,7]. It is documented that exogenous ligands like lipopolysaccharide (LPS) of bacteria, fungi and viruses can activate this receptor and cause immune responses [8]. Several experimental and clinical studies have suggested that there are anumber ofendogenousligands for hTLR4like fibrinogen, heat shock protein (HSP), minimally modified LDL, oxidized LDL, heparan sulfate and hyaluronan $[9,10]$. Activation of hTLR4 is followed by interaction with the adaptor protein, myeloid differentiation factor (MyD 88), and subsequent activation of nuclear factor kappa B (NF- $\kappa$ B). The eventual result is production of pro-inflammatory cytokines (e.g., IL-1 $\beta$, IL-6, and TNF- $\alpha$ ) [11-13]. Therewas an enhanced expression of hTLR4 on peripheral monocytes in patients with acute coronary syndromes compared with stable angina [14]. It has been suggested that TNF- $\alpha$ is linked with myocardial infarction and may potentially harm coronary arteries [15]. On the other hand, IL- $1 \beta$ is released by 
injured endothelial cells and may contribute to progression of atherosclerosis [16]. Angina pectoris represents an imbalance between myocardial oxygen supply and demand. Atherosclerotic disease of the coronary arteries, which leads to narrowing of the vessels, is the fundamental cause of angina pectoris. Medications, life-style modifications and revascularization techniques such as coronary artery bypass graftsurgery (CABG) or percutaneous coronary interventions (PCI), including balloon angioplasty and stents, are routine approaches to restoring this imbalance. Despite being on maximal medical therapy, some patients may suffer from angina and will experience revascularization therapies $[17,18]$. In the present study we evaluated the expression of hTLR4 on peripheral $\mathrm{CD} 14^{+}$monocytes in patients with stable angina who were on standard medications. Our goal was to find an association between hTLR4 expression and related pro-inflammatory cytokines with degree of coronary stenosis.

\section{MATERIALS AND METHODS}

\subsection{Study Patients}

The ethical board of Tabriz University of Medical Sciences approved the study and informed consent letter was obtained from all participants. Forty-fivepatients with diagnosis of coronary artery disease admitted to Shahid Madani Heart Hospital,Tabriz, Iran were included in the study. They were on standard treatments including routine medications, changing life style and weight reduction. They had complaints about various degrees of chest pain and other symptoms of angina like premature exhaustion and breathlessness. The exclusion criteria were as follows: autoimmune diseases (2 patients), inflammatory conditions (3 patients), advanced hepatic or renal disease and malignant neoplastic diseases (1 patient) and patients who receive glucocorticoids. None of the patients had valvular heart disease. Control group included 28 healthy volunteers who did not show symptoms of heart diseases. Cardiovascular risk factors, medications, sex, age and previous medical history wererecorded by questionnaires. White blood cell count, cholesterol, glucose, PT, PTT, BUN, creatinine, sodium and potassium were measured immediately after admission. All angiography procedures were performed according to the routine protocols of hospital.

\subsection{Analysis of Coronary Vessels}

Shortly, a guide wire and a catheter were inserted into the femoral artery. They freely passed up to the aorta. Patients routinely received 5000 units of heparin. Powerinjection of a contrast media was used to assess left ventricle function and coronary arteries. The severity of coronary artery lesionswas measured by comparing the area of narrowing to an adjacent normal segmentas a percentage reduction, and as a percentage reduction and calculated in the projection which demonstrates the most severe narrowing. This was done using Syngo software, Siemens, Germany.

\subsection{Blood Collection and Processing}

A total $6 \mathrm{ml}$ blood was drawn from patients with a 21gauge needle via antecubital venipuncture at time of admission. $2 \mathrm{ml}$ was kept in EDTA anticoagulant tubes for flowcytometry and the rest for analysis of biomarkers. $4 \mathrm{ml}$ of blood were centrifuged immediately $(3000 \times \mathrm{g}$ for $5 \mathrm{~min}$ ) to obtain serum. Serums were kept in $-80^{\circ} \mathrm{C}$ for future analysis.

\subsection{Flowcytometry Analysis}

Briefly, cells were stained at $4^{\circ} \mathrm{C}$ for 30 minutes with monoclonal antibodies for human CD14 (Abcam, UK) conjugated with fluorescein isothiocyanate (FITC) and hTLR4 (Abcam, UK) conjugated with phycoerythrin (PE). FITC and PE-conjugated non-specific mouse IgG2a antibodies were used for isotype controls (Abcam, UK). Cells were washed and cell-associated fluorescence was measured using a FACSCalibur flow cytometer (BD Biosciences, US). Data were analyzed by CellQuest software (BD Biosciences, US).

\subsection{Measurement of TNF- $\alpha$ and IL-1 $\beta$ by ELISA}

A sandwich enzyme-linked immunosorbent assay (ELISA) was performed (Ray Bio, US). In short, $100 \mu \mathrm{l}$ serum was added to microtiter plates. The incubation time was 2.5 hours at room temperature. After that, 100 $\mu \mathrm{l}$ prepared biothin antibody was added to each well and incubated for 1 hour at room temperature. Then $100 \mu \mathrm{l}$ streptavidin solution was added and incubated for 45 minutes at room temperature. The intensity of the color was measured at $450 \mathrm{~nm}$ by Stat Fax 2600 (Awareness Technology, US) plate reader. Stat Fax 2100 (Awareness Technology, US) was used for washing steps.

\subsection{Statistical Analysis}

Data are reported as mean \pm SD. Mann-Whitney U test was used to calculate differences between two independent variables. Categorical variables were compared using one-way analysis of variance. The correlation between hTLR4 and degree of coronary stenosiswere determined using Pearson test. Probability value $<0.05$ was considered to denote significant differences. All analyses were performed by SPSS 16 .

\section{RESULTS}

\subsection{Characteristics of Patients}

Biological and clinicaldata of 2 groups are summarized 
in Table 1. There were no significant differences in white blood cell count; medications including nitroglycerines, $\beta$ blockers, statins, antiplatelet drugs, or ACE inhibitors and risk factors among the patients.

\subsection{Coronary Artery Angiography}

Percentage stenosis diameter was calculated by coronary angiography. Patients showed various stenoses in different coronary arteries (Figure 1).

\subsection{Assessment of hTLR4 ${ }^{+} / \mathrm{CD}^{+} 4^{+}$Monocytes in Relation to Percentage Stenosis Diameter}

Protein levels of hTLR4 on the surface ofmonocytes were studied by flowcytometry analysis (Figures 2(a)(d)). A mean of $19.4 \% \pm 1.9 \%$ of CD14 $4^{+}$monocytes in patients with less severe stenosis showed surface expression for hTLR4 but did not reach statistical significance. Compared with healthy controls, patients with more severe stenosis showed a significantly higher monocytic hTLR4 expression $(15.1 \% \pm 2.3 \%$ versus $29.3 \% \pm 3.7 \%$; $p<0.01$ ) (Figure 2(e)).

\subsection{Serum Levels of TNF- $\alpha$ in Relation to Percentage Stenosis Diameter}

Circulating serum TNF- $\alpha$ levels were significantly lower

Table 1. Baseline characteristics and labaratory parameters of patients and control.

\begin{tabular}{|c|c|c|}
\hline Characteristics & Control $(n=28)$ & Patients $(\mathrm{n}=39)$ \\
\hline Age, years & $41 \pm 10$ & $52 \pm 8$ \\
\hline Male & $25(89.2)$ & $27(69.2)$ \\
\hline Hypertension & $\ldots$ & $22(56.4)$ \\
\hline Diabetes & $\ldots$ & $24(61.5)$ \\
\hline Hyperlipidemia & $\ldots$ & $14(35.8)$ \\
\hline Familial history & $\ldots$ & 7 (17.9) \\
\hline Smoking & $\ldots$ & $11(28.2)$ \\
\hline Medications & $\ldots$ & \\
\hline Nitrates & $\ldots$ & $23(58.9)$ \\
\hline$\beta$ Blockers & $\ldots$ & $29(74.3)$ \\
\hline $\mathrm{ACE}^{1}$ inhibitors & $\ldots$ & $10(25.6)$ \\
\hline A2 blockers & $\ldots$ & 7 (17.9) \\
\hline Calcium channel blockers & $\ldots$ & $4(10.2)$ \\
\hline Statins & $\ldots$ & $34(87.1)$ \\
\hline $\mathrm{ASA}^{2}$ & $\ldots$ & $31(79.4)$ \\
\hline \multicolumn{3}{|l|}{ Laboratory parameters } \\
\hline C-reactive protein (mg/dl) & $0.2 \pm 0.1$ & $0.5 \pm 1.3$ \\
\hline Cholesterol (mg/dl) & $180 \pm 36$ & $192 \pm 37$ \\
\hline LDL (mg/dl) & $121 \pm 20$ & $139 \pm 21$ \\
\hline HDL (mg/dl) & $42 \pm 8$ & $40 \pm 9$ \\
\hline Glucose (mg/dl) & $95 \pm 11$ & $99 \pm 21$ \\
\hline White blood cell count (U/L) & $7.2 \pm 0.3$ & $7.2 \pm 0.4$ \\
\hline
\end{tabular}

Data are shown in number (\%) or mean \pm SD. 1 : angiotensin converting enzyme; 2: acetyl salicylic acid.

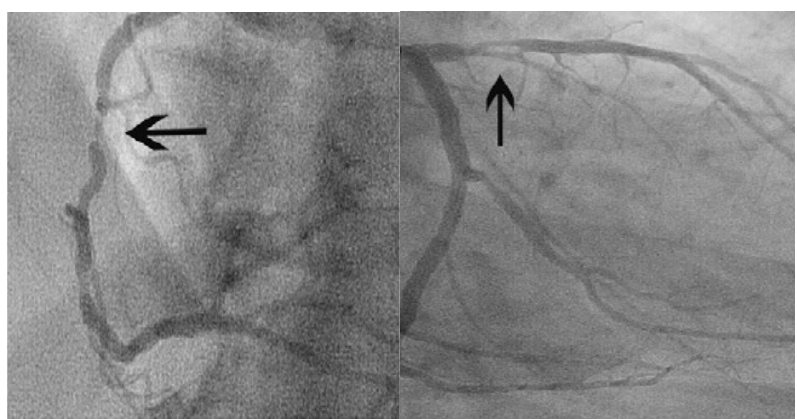

(a)

(b)

Figure 1. Stenosis in the right coronary artery (a); Stenosis in the proximal left anterior descending artery (b).
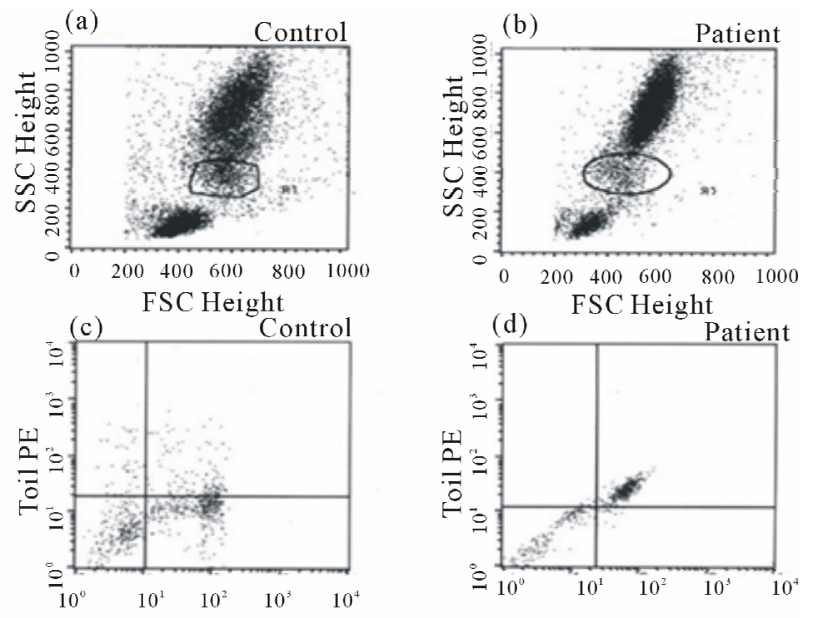

CD14 FITC

CDI4 FITC

(e)

- Control $\quad=<60 \%$

$->60 \%$

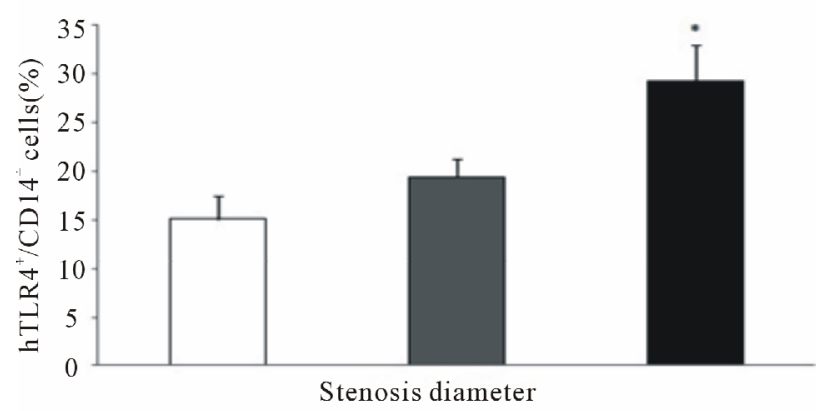

Figure 2. Gating monocyte population in the samples of controls and patients ((a) and (b)). Representative dot plot showing hTLR $4^{+} /$CD $14^{+}$monocytes in controls and patients with stable angina ((c) and (d)). Data are shown as mean \pm SD. Ten thousand cells were analyzed by flowcytometry in relation to percentage stenosis diameter (\%) of the diseased vessel (e); ${ }^{*} p<$ 0.01 vs control.

in controls than in patients with more severe stenosis $(11.1 \pm 2.2$ versus $21.5 \pm 3.1 \mathrm{pg} / \mathrm{ml} ; p<0.05)$ (Figure 3$)$. A Similar relation was seen in patients with less severe stenosis,but it was not statistically significant. 


$$
\text { aControl a }<60 \% \quad \text { - }>60 \%
$$

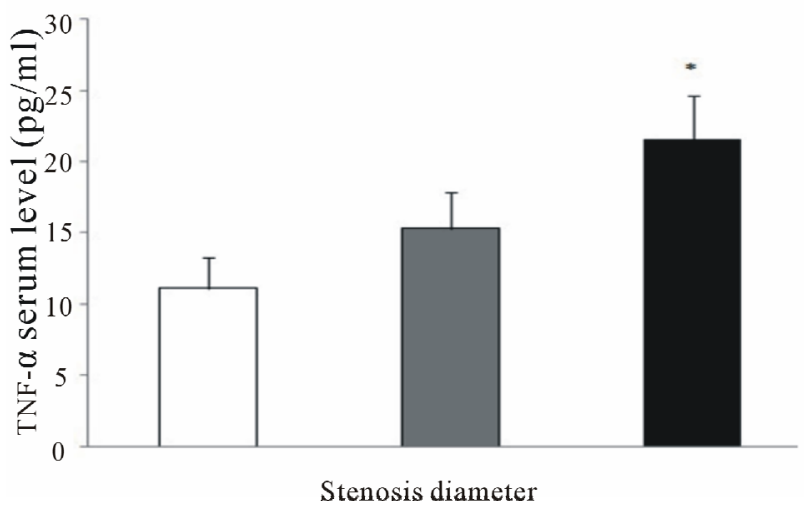

Figure 3. Serum levels of TNF- $\alpha$ measured by ELISA. Patients with more severe coronary stenosishad higher serum levels of TNF- $\alpha$ than other patients or controls; ${ }^{*} p<0.05$ vs control.

\subsection{Serum Levels of IL-1 $\beta$ in Relation to Percentage Stenosis Diameter}

In comparison with controls, patients with more severe coronary occlusionexhibited higher levels of IL-1 $\beta$ (8.4 \pm 2.4 versus $13.8 \pm 1.8 \mathrm{pg} / \mathrm{ml}$ ) (Figure 4 ).

\subsection{Pearson Correlations}

Strong correlationwas seen between the frequency of circulating hTLR $4^{+} / \mathrm{CD} 14^{+}$monocytes and the percentage of coronary luminal stenosis $(r=0.5$ and $p=0.05$ ) (Figure 5). A significant correlation was noted between the frequency of serum levels of TNF- $\alpha$ and coronary luminal stenosis ( $\mathrm{r}=0.40$ and $p=0.05$ ) (Figure 6). Despite positive association between serum levels of IL- $1 \beta$ and coronary stenosis, it failed to reach a significant correlation.

\section{DISCUSSION}

In thisinvestigation we used flowcytometry and ELISA to describe an association between monocyte expression levels of hTLR4 and its related signaling events with percentage diameter stenosis of the coronary arteries. Patients with lower stenosis diameter expressed lower expression of hTLR4 as well as lower serum levels of both TNF- $\alpha$ and IL-1 $\beta$. Notably, enhanced expression of hTLR4 was associated with elevations of IL- $1 \beta$ and TNF- $\alpha$. Evidence is accumulating that outward arterial remodeling is associated with vulnerable plaque phenotype [19] and increase in hTLR4 expression [20]. Ameziane et al. [21] showed that polymorphism of Gly299 allele of the hTLR4 gene is associated with reduction in acute coronary events. It is believed that upregulation of hTLR4 contributes to activation of monocytes, whereas downregulation can suppress proinflammatory responses [22]. Elevated release of IL- $1 \beta$ and TNF- $\alpha$ in link with

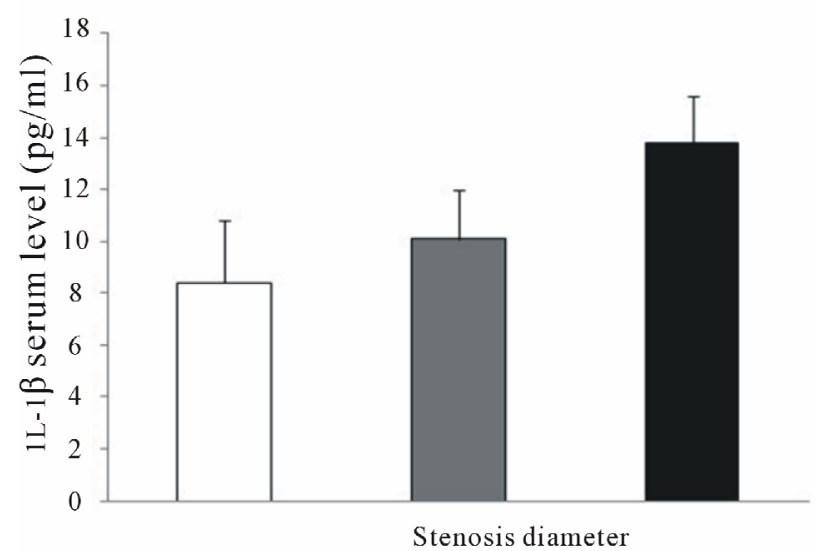

Figure 4. Serum levels of IL- $1 \beta$ measured by ELISA. Patients with more severe coronary stenosis showed higher serum levels of IL- $1 \beta$ than other patients or controls.

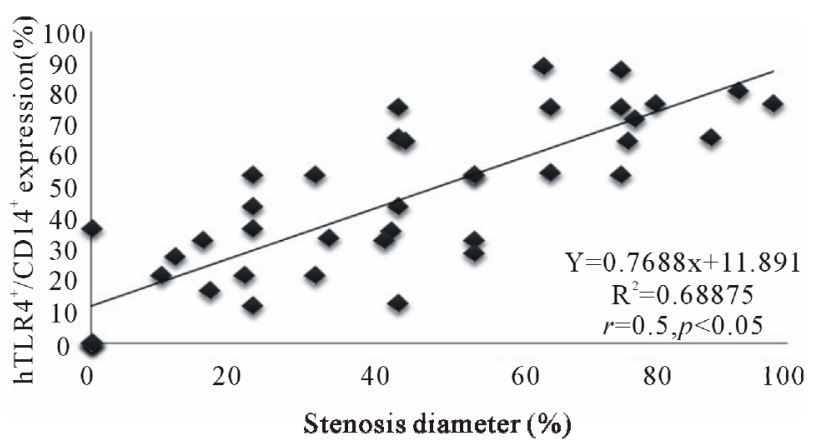

Figure 5. Correlation between hTLR $4^{+} / \mathrm{CD} 14^{+}$monocytes and percentage stenosis diameter.

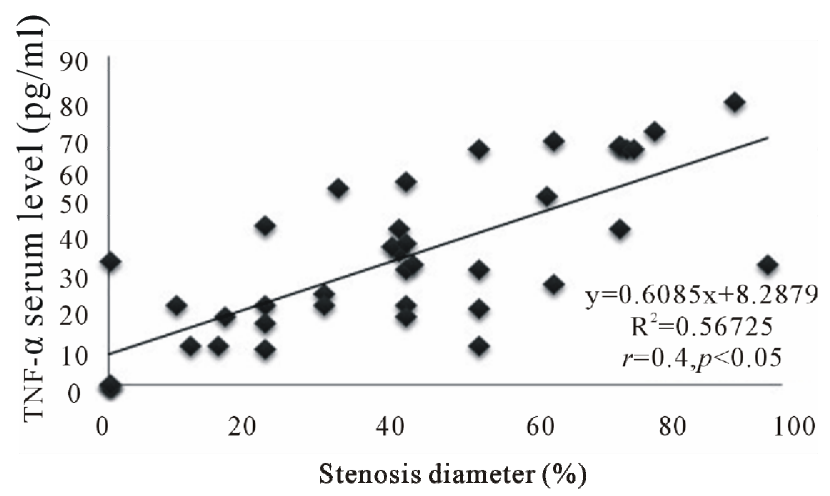

Figure 6. Correlation between serum levels of TNF- $\alpha$ and percentage stenosis diameter.

antigen presentation has been shown to activate $\mathrm{T}$ cells and cause differentiation into T-helper 1 cells [11,23], which may cause plaque instability [24]. Versteeg et al. [25] provided evidence that hTLR 4 responsewas associated with thepercentage diameter stenosis and the number of the diseases vessels. In comparison with our work, they used a different method and focused on TNF- 
$\alpha$ concentration. Akira and colleagues [26] showed that hTLR4 signaling pathway may have central role in the production of proinflammatory cytokines. Serum concentrations of TNF- $\alpha$ and mRNA expression of hTLR4 in peripheral monocytes are significantly increased after thrombolysis therapy [15]. Some animal studies proved that during 30 minutes of ischemia followed by reperfusion, elevated expression of hTLR4 mRNA was positively correlated with both TNF- $\alpha$ expression and its serum concentration [27]. Björkbacka et al. [28] found that that My d88-deficient mice showed a marked reduction in early stages of atherosclerosis. Moreover, Michelsen et al. showed that lack of TLR4 results in reduction of atherosclerosis in mice [29]. A study showed that direct inhibition of TLR4 could significantly reduce the detrimental effects of myocardial ischemia reperfusion [30]. Those findings were further supported by the point, thath TLR4 deficiency leads to alteration in lipid content of atherosclerotic plaque and reduces macrophage infiltration. Taken together, the findings of the present investigation may set a link between hTLR4 expression and proinflammatory cytokines with coronary stenosis. Outward arterial remodeling is thought to be the primary cause of atherosclerosis and restenosis [31]. In vitro studies showed that TLR4 is involved in arterial remodeling [32]. Additionally, it is believed that increase in serum levels of proinflammatory cytokines is associated with CAD [33,34]. We demonstrated that lower degree of stenosis leads to lower monocyte expression and response of hTLR4. It should be noted that hTLR4 involvement in coronary stenosis is not mechanistically understood. It is proposed that gradual infiltration of hTLR $4^{+}$monocytes in developing plaques and production of cytokines in concert with other important players can deteriorate atherosclerosis. Our prior study revealed a positive correlation between hTLR4 monocyte expression and serum levels TNF- $\alpha$ and IL- $1 \beta$ in patients with SA who underwent percutaneous coronary intervention [35]. Upregulation in hTLR4 and pro-inflammatorycytokines and increased arterial remodeling may impair vasodilatation, reduce coronary flow and thus contribute to facilitate ischemic damages [33,34]. It is noteworthy that inflammation plays its distinguished role not only inside the atherosclerotic plaques, but also in systemic blood circulation. The determining factor for this increase in systemic inflammatory responses remains unknown. However, these eventsmay partially explain the refractoriness to medications in patients with chronic SA who need revascularization therapies. As plaque encroaches into the lumen, the coronary artery diameter decreases. Luminal narrowing of more than 60 percent may result in transient ischemia and angina. More importantly, there is a poor correlation between the severity of steno- sis and its propensity to cause myocardai infarction or sudden cardiac death. Currently it is believed that inhibition of hTLR4 or hTLR4 related downstream activity can subsequently attenuate plaque formation or even plaque rupture $[35,36]$. Of note, formation of collateralarteriogenesis which is an important mechanism to increase blood flow to ischemic parts $[37,38]$ is mediated by inflammatory cytokines [39,40]. The beneficial effects of hTLR4 in arteriogenesis were seen by Grote study [41]. Thus, a paradox exists in which enhanced expression of hTLR4 haspositive role in arteriogenesis and increases the likelihood of events that results in plaque formation, instability and rupture. Future experimental and clinical studies should provide more perception about hTLR4 role in coronary artery disease. Methe's study revealed that statins decreased monocyte expression of hTLR4 [42]. Quite recent data showed that simvastatin or the combination of simvastatin with ezetimibe reduced TLR4 expression and IL- 6 and IL- $1 \beta$ production in monocytes of hypercholesterolemic patients [43]. Our studied patients did not show significant differences in the medications and despite being on statin treatment, patients with more severe stenosis exhibited higher expression of hTLR4, suggesting the role of hTLR4 in deterioration of ischemic heart disease. In conclusion, our study demonstrated that hTLR4 monocyte expression and pro-inflammatory cytokines are positively associated with the degree of coronary stenosis. These findings may emphasize the potential role of hTLR4 in CAD.

\section{ACKNOWLEDGEMENTS}

This study was a PhD project No.57 supported by a grant from vice chancellor for research of Tabriz University of Medical Sciences. The authors wish to thank the staff of Shahid Madani Heart Hospital. The authors declare that there are no conflicts of interests.

\section{REFERENCES}

[1] Ross, R. (1999) Atherosclerosis-An inflammatory disease. New England Journal of Medicine, 340, 115-126. doi:10.1056/NEJM199901143400207

[2] Glass, C. and Witztum, J. (2001) Atherosclerosis: The road ahead. Cell, 104, 503-516. doi:10.1016/S0092-8674(01)00238-0

[3] Bennet, M.R. (1999) Apoptosis of vascular smooth muscle cells in vascular remodeling and atherosclerotic plaque rupture. Cardiovascular Research, 41, 361-368. doi:10.1016/S0008-6363(98)00212-0

[4] Takeda, K. and Akira, S. (2005) Toll-like receptors in innate immunity. International Immunology, 17, 1-14. doi:10.1093/intimm/dxh186

[5] Kaisho, T. and Akira, S. (2006) Molecular mechanisms in allergy and clinical immunology. Journal of Allergy and Clinical Immunology, 117, 979-987. doi:10.1016/j.jaci.2006.02.023 
[6] Vink, A., Schoneveld, H.A., Van der Meer, J., et al. (2001) In vivo evidence for a role of Toll-like receptor 4 in the development of intimal lesions. Circulation, 104, 3103-3108.

[7] Fishbein, M., Luthringer, D., Xu, X., et al. (2001) Tolllike receptor-4 is expressed by macrophages in murine and human lipid-rich atherosclerotic plaques and upregulated by oxidized LDL. Circulation, 104, 3103-3108. doi:10.1161/hc5001.100631

[8] McDermott, E. and O’Neill, L. (2004) Signal transduction by the lipopolysaccharide receptor, Toll-like recaptor-4. Journal of Immunology, 113, 153-162. doi:10.1111/j.1365-2567.2004.01976.x

[9] Tsan, M. and Gao, B. (2004) Endogenous ligands of Tolllike receptors. Journal of Leukocyte Biology, 76, 514-519. doi:10.1189/jlb.0304127

[10] Ohashi, K., Burkart, V., Flohé, S. and Kolb, H. (2000) Cutting edge: Heat shock protein 60 is a putative endogenous ligand of the Toll-like receptor-4 complex. Journal of Immunology, 164, 558-561.

[11] Miller, Y., Viriyakoso, S., Binder, C., Feramisco, J., Kirkland, T. and Witztum, J. (2003) Minimally modified LDL binds to CD14, induces macrophage spreading via TLR4/MD-2, and inhibits phagocytosis of apoptotic cells. Journal of Biological Chemistry, 278, 1561-1568.

[12] Schnare, M., Barton, G., Holt, A., Takeda, K., Akira, S. and Medzhitov, R. (2001) Toll-like receptors control activation of adaptive immune responses. Nature Immunology, 41, 947-950. doi:10.1038/ni712

[13] Frantz, S. and Bauersachs, J. (2010) Toll-like receptors: Emerging therapeutic targets for heart failure. Heart and Metabolism, 47, 19-22.

[14] Methe, H., Kim, J., Kofler, S., Weis, M., Nabauer, M. and Koglin, J. (2005) Expansion of circulating Toll-like receptor 4-positive monocytes in patients with acute coronary syndrome. Circulation, 111, 2654-2661. doi:10.1161/CIRCULATIONAHA.104.498865

[15] Irwin, M.W., Mak, S., Mann, D.L., et al. (1999) Tissue expression and immunolocalization of tumor necrosis factor- $\alpha$ in post infarction dysfunctional myocardium. Circulation, 99, 1492-1498. doi:10.1161/01.CIR.99.11.1492

[16] Dinarello, C.A. and Wolff, S. (1993) The role of interleukin-1 in disease. New England Journal of Medicine, 328, 106-112. doi:10.1056/NEJM199301143280207

[17] Kim, C. M., Kini, A. and Sharma, K.S. (2002) Refractory angina pectoris: Mechanism and therapeutic options. Journal of the American College of Cardiology, 39, 923-934. doi:10.1016/S0735-1097(02)01716-3

[18] Abrams, J. (2005) Chronic stable angina. New England Journal of Medicine, 352, 2524-2533. doi:10.1056/NEJMcp042317

[19] Hollestelle, S.C., De Vries, R.M., Van Keulen, J.K., et al. (2004) Toll-like receptor 4 is involved in outward arterial remodeling. Circulation, 109, 393-398. doi:10.1161/01.CIR.0000109140.51366.72

[20] Pasterkamp, G., Schoneveld, H.A., Van Derwal, A., et al. (1998) Relation of arterial geometry to luminal narrowing and histologic markers for plaque vulnerability: The remodeling paradox. Journal of the American College of Cardiology, 32, 655-662. doi:10.1016/S0735-1097(98)00304-0

[21] Ameziane, N., Beillat, T., Verpilla, P., et al. (2003) Association of the Toll-like receptor 4 gene Asp299Gly polymorphism with acute coronary events. Arteriosclerosis, Thrombosis, and Vascular Biology, 23, e61-e64. doi:10.1161/01.ATV.0000101191.92392.1D

[22] Medvedev, E.A., Kopydlowski, K.M. and Vogel, N.S. (2000) Inhibition of lipopolysaccharide-induced signal transduction in endotoxin-tolerized mouse macrophages: Dysregulation of cytokine, chemokine, and Toll-like receptor 2 and 4 gene expression. Journal of Immunology, 164, 5564-5574.

[23] Takeshita, F., Tanaka, T., Matsuda, T., et al. (2006) TollLike Receptor adaptor molecules enhance DNA-raised adaptive immune responses against influenza and tumors through activation of Innate Immunity. Journal of Virology, 80, 6218-6224. doi:10.1128/JVI.00121-06

[24] Methe, H., Brunner, S., Wiegand, D., Nabauer, M. and Koglin, J. (2005) Enhanced T-Helper-1 lymphocyte activation patterns in acute coronary syndromes. Journal of the American College of Cardiology, 45, 1939-1945. doi:10.1016/j.jacc.2005.03.040

[25] Versteeg, D., Hoefer, I.E., Schoneveld, A.H., et al. (2008) Monocyte Toll-Like Receptor 2 and 4 response and expression following percutaneous coronary intervention: Association between lesion stenosis and fractional flow reserve. Heart, 94, 770-776. doi:10.1136/hrt.2007.117259

[26] Akira, S. and Hemmi, H. (2003) Recognition of pathogen-associated molecular patterns by TLR family. Immunology Letters, 85, 85-95.

[27] Yang, J. and Ding, J. (2008) Sequential expression of TLR4 and its effects on the myocardium of rats with myocardial ischemia-reperfusion injury. Inflammation, 31, 304-312. doi:10.1007/s10753-008-9079-x

[28] Björkbacka, H., Kunjathoor, V., Moore, K., et al. (2004) Reduced atherosclerosis in MyD88-null mice links elevated serum cholesterol levels to activation of innate immunity signaling pathways. Nature Medicine, 10, 416421. doi: $10.1038 / \mathrm{nm} 1008$

[29] Michelsen, K., Kathrin, S., Wong, M., et al. (2004) Lack of Toll-like receptor 4 or myeloid differentiation factor 88 reduces atherosclerosis and alters plaque phenotype in mice deficient in apolipoprotein E. Proceedings of the National Academy of Sciences of the United States of America, 101, 10679-10684. doi:10.1073/pnas.0403249101

[30] Shimamoto, A., Chong, A., Yada, M., et al. (2006) Inhibition of Toll-like receptor 4 with eritoran attenuates myocardial ischemia-reperfusion injury. Circulation, 114, 270-274. doi:10.1161/CIRCULATIONAHA.105.000901

[31] Schoenhagen, P., Ziada, K.M., Kapadia, R.S., Crowe, D.T., Nissen, E.S. and Tuzcu, E.M. (2000) Extent and direction of arterial remodeling in stable versus unstable coronary syndromes. Circulation, 101, 598-603. doi:10.1161/01.CIR.101.6.598

[32] Bagheri, B., Sohrabi, B., Movassaghpour, A., et al. (2012) 
Monocyte expression of toll-like receptor-4 in patients with stable angina undergoing percutanoeus coronary intervention. Iranian Journal of Immunology, 9, 149-158.

[33] Ikonomidis, I., Andreotti, F., Economou, E., Stefanadis, C., Toutouzas, P. and Nihoyannopoulos, P. (1999) Increased proinflammatory cytokines in patients with chronic stable angina and their reduction by aspirin. Circulation, 100, 793-798. doi:10.1161/01.CIR.100.8.793

[34] Bhagat, K. and Vallance, P. (1997) Inflammatory cytokines impair endothelial dependent dilatation in human veins in vivo. Circulation, 96, 3042-3047. doi:10.1161/01.CIR.96.9.3042

[35] Hansson, G.K., Libby, P., Schonbeck, U. and Yan, Z.Q. (2002) Innate and adaptive immunity in the pathogenesis of atherosclerosis. Circulation Research, 91, 281-291. doi:10.1161/01.RES.0000029784.15893.10

[36] Iechl, S., Lorenz, E., Reindl, M., et al. (2002) Toll-like receptor 4 polymorphisms and atherogenesis. New England Journal of Medicine, 347, 185-192. doi:10.1056/NEJMoa012673

[37] Heil, M. and Schaper, W. (2004) Influence of mechanical, cellular, and molecular factors on collateral artery. Circulation Research, 95, 449-458.

[38] Deindl, E. and Schaper, W. (2005) The art of arteriogenesis. Cell Biochemistry and Biophysics, 43, 1-15.

$$
\text { doi:10.1385/CBB:43:1:001 }
$$

[39] Hoefer, I.E., Van, R.N. and Rectenwald, J.E. (2002) Direct evidence for tumor necrosis factor-alpha signaling in arteriogenesis. Circulation, 105, 1639-1641. doi:10.1161/01.CIR.0000014987.32865.8E

[40] Yoshida, J., Ohmori, K. and Takeuchi, H. (2005) Treatment of ischemic limbs on local recruitment of vascular endothelial growth factor-producing inflammatory cells with ultrasonic microbubble destruction. Journal of the American College of Cardiology, 46, 899-905. doi:10.1016/j.jacc.2005.05.052

[41] Grote, K., Schütt, H. and Schieffer, B. (2011) Toll-like receptors in angiogenesis. Science World Journal, 11, 981-991. doi:10.1100/tsw.2011.92

[42] Methe, H., Kim, J., Kofler, S., Weis, M., Nabauer, M. and Koglin, J. (2005) Statins decrease Toll-like receptor 4 expression and downstream signaling in human CD14+ monocytes. Circulation, 25, 1439-1445.

[43] Moutzouri, E., Tellis, C., Rousouli, K., et al. (2012) Effect of simvastatin or its combination with ezetimibe on Toll-like receptor expression and lipopolysaccharide-induced cytokine production in monocytes of hypercholesterolemic patients. Atherosclerosis, 225, 381-387. doi:10.1016/j.atherosclerosis.2012.08.037 